\title{
Cogitation on the Training of Psychological Education in Schools
}

\author{
Xuelian Lu \\ Tonghua Normal University, College of Education Science, Jilin Province, Tonghua City, 134002, \\ China. \\ luxuelian1982@sina.com
}

\begin{abstract}
It has very important significance on promoting the long-term development of the school work and team building for schools, so the writer proposed that schools should try to grasp the psychological education training and enhance the quality and effectiveness of education. In order to improve the quality and efficiency of psychological education training, schools should try their best to do it in three aspects: first, to improve the awareness of "how to grasp it reasonably "; second, to innovate the methods and solve the problem of "how to teach and how to train" effectively; third, to broaden the channels of dealing with the problem "how to train talents"; last but not least, to solve the problem of "how to measure".
\end{abstract}

Keywords: Educational pool efforts; innovative methods; the combination of internal and external work; content- focused; scientific evaluation.

\section{抓好学校心理教育训练的几点思考}

\author{
陆雪莲 \\ 通化师范学院教育科学学院, 吉林通化 中国
}

摘 要: 抓好学校心理教育训练工作, 进一步增强学校教育教学工作的质量和效果, 对推进学校 工作和队伍建设长远发展具有非常重要的意义。提高学校心理教育训练工作的质量和效益, 一要提高认识, 切实解决好 “怎么合理抓” 的问题; 二要创新方法, 切实解决好 “怎么教、怎 么训” 的问题; 三要拓宽渠道, 切实解决好 “怎么培养人才” 的问题; 四要科学评估, 切实解 决好 “怎么衡量效果”的问题。

关键词: 教育合力; 创新方法; 内外结合; 注重内容; 科学评估

\section{1. 前言}

心理教育训练是采用一定的心理学方法, 有意识、有目的地对学生心理过程、个性心理 特征和心理状态施加影响, 使其形成学习生活所需要的心理素质、以提升学习效果和身心健 康水平。认真落实《中小学心理健康教育指导纲要》（2012 年修订），抓好学校心理教育训 练, 是进一步加强和改进学校德育工作、全面推进素质教育的重要组成部分。

\section{2. 着力解决 “四问题”, 努力提高学校心理教育训练工作的质量和效益}

2. 1. 提高认识：切实解决好 “怎么合理抓” 的问题

学校在心理教育训练方面效果不够好, 或质量不够高, 原因是多方面的, 但主要还是思 想不重视, 认识上不去, 无法真正形成教育合力。

2. 1.1 转变思想是形成教育合力的前提

学校心理教育训练过程中, 往往存在两种不良思想倾向, 值得学校工作人员注意。一个 
是心理教育训练是单纯的德育工作的思想, 认为心理教育训练由德育校长牵头, 那就是德育 教研室的事、德育教师的事, 导致教育容易实施, 而训练和硬件建设上的事则难协调、难落 实。另一个是畏难情绪, 有的工作人员感到心理教育训练经费、心理专业人员、教材和器材 等, 学校基层教师都没有能力解决, 存在等靠思想。因此, 要把端正态度、提高认识作为抓 心理教育训练落实的前提, 学校中心组理论学习也好, 教育教学训练也好, 都要突出心理教 育训练的地位作用, 认真抓好《中小学心理健康教育指导纲要》(2012 年修订) 学习教育, 帮助所有教师充分认清心理教育训练的重要性, 树立抓心理教育训练就是抓学校发展、抓学 生成才的思想, 增强抓落实促成效的自觉性和主动性。

2.1 .2 健全制度是形成教育合力的关键

学校心理教育训练之所以抓落实零打碎敲、断断续续, 主要是没有以制度的形式把心理 教育训练固定下来、开展下去。在心理教育训练上, 学校各级各部门必须建立目标规划、形 势分析、检查评比、考核验收、奖励激励等长效机制, 确保能够将心理教育训练摆上位, 并 定期抓、长期抓、高效抓。

2.1.3 明确责任是形成教育合力的重点

责任不清、分工不明，是工作不落实的重要原因。反思学校心理教育训练过程中训练不 到位, 原因就是有的学校机关抓、基层不抓, 德育教师抓、任课教师不抓，特别是有的学校 业务部门之间, 存在相互推卸责任现象。心理指导纲要对心理教育和训练的组织领导, 规定 要求得非常明确。我们必须在坚持学校统一抓、主管亲自抓的同时, 对教育、训练、配套建 设、人才培养等问题进行明确分工, 明确责任, 落实到具体部门、具体人员, 特别是主抓教 育和训练的业务部门, 要专人专管, 任课教师中要设立专门的骨干, 通过层层落实责任制, 切实形成上下拧成一股绳的局面。

2. 2. 创新方法：切实解决好 “怎么教、怎么训” 的问题

要把心理教育作为学年德育工作的重要内容, 在教育方法上要通盘研究考虑, 制定出具 体可行的落实计划。

\section{2.1 心理教育要与其他教育结合抓}

心理教育是德育工作的重要内容, 培育学生健康的学习与生活意志, 打造学生过硬的心 理素质, 需要打牢坚定的理想信念和崇高的道德基础。要注重把培养学生不畏辛苦、自主吃 苦耐劳的意识心理品质，贯穿理想信念教育之中，渗透学习精神教育全过程。

2.2 .2 心理教育要集中时间系统抓

心理教育不同于一般德育工作的方面就在于注重从生理角度, 帮助学生正确认识和解决 存在的心理问题。了解掌握心理基本知识, 克服心理障碍, 不是上一二节课能达到目的的, 必须相对集中安排时间, 科学设置内容, 通过系统教育和连续教育, 达到由浅入深、逐步融 会贯通的目的。

2.2 .3 心理教育要外请专家辅导抓

心理教育和疏导是一个新课题, 专业性强, 学校现有的心理教育教师在教育中讲不深、 讲不透的现象比较普遍。因此, 要注重借助师范院校和地方教育资源优势, 请心理教育及辅 导专家为学生授课辅导, 破解心理难题, 提高教育层次和效果。

2.2 .4 心理教育要开展活动配合抓

通过开展心理知识竞赛、组织心理咨询、轮流上台演讲等学生喜闻乐见的活动，配合心 理教育, 广大教育效果。心理素质, 既有遗传因素, 也有后天环境影响的原因。要使学生心 理素质发生质的变化，是个慢功夫，必须循序渐进、潜移默化地进行系统心理训练。

根据学校学年训练情况, 强化心理训练大体可分为四步走。第一步, 在集中学习中强化。 训练展开前, 要安排专门时间, 组织学生接受学习心理训练方面的有关常识, 帮助学生掌握 基本方法, 端正态度, 打消顾虑, 为搞好训练奠定基础。第二步, 在训练器材上强化。通过 在训练器材上由简到难反复训练, 实现学生由畏难到轻松自如的心理转变。心理训练器材要 求具备一定的科技含量, 学校自己研发有一定困难, 因此必须坚持自主研制、校校配合与上 
级配发相结合, 努力实现教材配套、设施配套和场地配套。第三步, 在实践课程中强化。实 践课程难度大、标准高、要求严, 是培养提高学生心理素质的有利时机。要围绕提高心理素 质, 注意设计好实践课程教学中每个环节重点培养锻炼的目标和方法, 以培育学生过硬心理 素质和顽强意志。让学生在体验生活的同时, 感到身心的愉悦, 重塑自己的人生观和价值观, 逐渐成为一个自信、自立、自强的人。

\section{3. 拓宽渠道: 切实解决好 “怎么培养人才” 的问题}

目前, 学校心理教育训练专业人才比较缺乏。要解决这个 “瓶颈” 问题, 必须拓宽视野, 开拓渠道, 走内外结合的培养路子。

2. 3.1 靠自己培养

要克服等靠思想, 调动在校教师学习钻研心理学知识的积极性, 特别是要组织心理教育 训练骨干, 刻苦钻研心理健康教育及心理教育训练有关知识, 深入研究有效实用的教育训练 措施, 提高组织心理教育训练的能力。

2. 3.2 送高师院校培训

高师院校是心理咨询、教育和疏导专业骨干生长的主渠道, 每年都要选送一定数量的教 师进高师院校学习心理教育训练专业知识, 加强人才培养, 努力提高学校心理骨干的专业素 质, 以尽快提高学校心理健康教育专业人员的数量和质量。

2.3.3 借鉴外校经验

在心理健康教育和心理教育训练上, 要积极吸收他校之长, 借鉴其成功经验, 为其所用。 吸取外校独具特色的心灵对比法, 达到心灵沟通, 不教而教的效果; 相信学生有才, 帮助学 生成才, 始终相信学生的潜能是无限的。

2. 4. 科学评估: 切实解决好 “怎么衡量效果” 的问题

评估体系是心理教育训练体系链中的最后一环, 也是非常重要的一环, 对不断完善发展 心理教育训练有极大的促进作用。在心理教育训练效果评估上, 目前学校办法还不是很多, 相关高师院校人员和相关部门也正加紧这方面的研究。

根据学校现实情况, 建立心理教育训练评估体系应涵盖: 一是组织实施方面, 要把动态 考评与静态考评、定性考评与定量考评、随即考评与定期考评、形成性评价和终结性评价结 合起来, 把考核教育情况与考核训练情况结合起来, 构成心理素质训练课评价标准。二是考 核内容方面, 要考核心理知识的掌握情况, 心理教育训练操作准确情况, 模拟实际训练背景 刺激下的心理恐慌情况, 平时生活工作中的表现情况等。三是考核手段方面, 要注意教育后 及时考评, 任务中全面观察, 专用仪器定期测试, 心理医生定期质询, 并建立人员心理档案, 记录考核情况; 要研制专门的评估软件, 每年对所属人员心理情况进行综合评估, 给出科学 判断。

\section{3. 结论}

提高学校心理教育训练工作的质量和效益, 既要提高认识以切实解决好 “怎么合理抓” 的 问题, 又要创新方法以切实解决好 “怎么教、怎么训” 的问题, 也要拓宽渠道以切实解决好 “怎么培养人才” 的问题, 更要科学评估以切实解决好 “怎么衡量效果” 的问题。抓好学校 心理教育训练工作, 进一步增强学校教育教学工作的质量和效果, 对推进学校工作和队伍建设 长远发展具有非常重要的意义。

\section{致谢}

1. 吉林省教育科学 “十二五” 规划课题《初中生心理健康教育实践研究》阶段性成果, 项目编号: GH12409

2. 吉林省教育科学 “十二五” 规划重点课题《吉林省长白山地区农村中学教师课程执行 力研究》阶段性成果, 项目编号: ZD14101 


\section{References}

[1]. Lan Jiao .Pay attention to the evaluation and improve the effect of mental health education [J]. China Higher Education.2014 seventh, P56-57.

[2]. Huaiying Qu. Mental health education -- a sign of school development [J]. Life Education.2014 fifth, P160-161.

[3]. Junping Zhao. Application of group counseling in mental health education in schools [J]. Journal of Education Institute of Taiyuan University. June 2011 twenty-ninth volume second, $\mathrm{P} 22-25$.

[4]. Wei Sun. Growth training camp: an effective form of mental health education in rural schools [J]. Mental Health Education in Primary and Secondary School. 2007 fifth, P13-15.

[5]. Xiaodong Hua. A preliminary study on the application of the coach self - service training method in the school psychological education. [J]. Popular Psycholo.2007 sixth, P33-35. 